\title{
Absorbed dose calculations for macromolecular crystals: improvements to RADDOSE. Erratum
}

\author{
Karthik S. Paithankar, Robin Leslie Owen and Elspeth F. Garman
}

J. Synchrotron Rad. (2018). 25, 627-628

\section{A IUCr Journals \\ CRYSTALLOGRAPHY JOURNALS ONLINE \\ Copyright (C) International Union of Crystallography \\ Author(s) of this paper may load this reprint on their own web site or institutional repository provided that this cover page is retained. Republication of this article or its storage in electronic databases other than as specified above is not permitted without prior permission in writing from the IUCr. \\ For further information see http://journals.iucr.org/services/authorrights.html}


JOURNAL OF SYNCHROTRON RADIATION
Received 5 February 2018

Accepted 5 February 2018

\section{Absorbed dose calculations for macromolecular crystals: improvements to RADDOSE. Erratum}

\author{
Karthik S. Paithankar, ${ }^{\mathrm{a}}$ Robin Leslie Owen ${ }^{\mathrm{a}, \mathrm{b}} \neq$ and Elspeth F. Garman ${ }^{\mathrm{a} *}$ \\ a'Laboratory of Molecular Biophysics, Department of Biochemistry, University of Oxford, South Parks Road, \\ Oxford OX1 3QU, UK, and ${ }^{\mathbf{b}}$ Swiss Light Source, Paul Scherrer Institut, CH-5232 Villigen PSI, Switzerland. \\ *Correspondence e-mail: elspeth.garman@bioch.ox.ac.uk
}

Corrections to an equation and a figure in the paper by Paithankar et al. (2009). [J. Synchrotron Rad. 16, 152-162] are made.

‡ Present address: Diamond Light Source Ltd, Diamond House, Harwell Science and Innovation Campus, Didcot, Oxfordshire OX11 0DE, UK.

Keywords: absorbed dose; macromolecular crystallography; experimental dose limit; fluorescence escape; photoelectric absorption

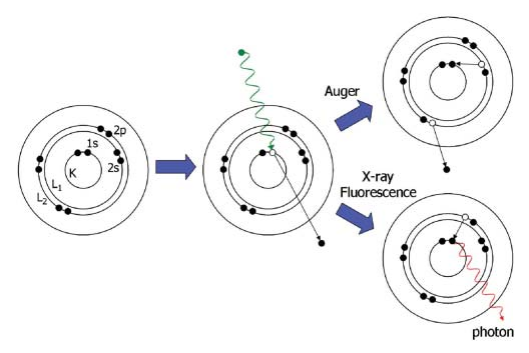

(C) 2018 International Union of Crystallography
Correct versions of equation (5) and Fig. 4 and its legend in the paper by Paithankar et al. (2009). [J. Synchrotron Rad. 16, 152-162] are given. The last line on page 155 and equation (5) on page 156 should read as follows:

The fraction of $\mu_{\mathrm{pe}}$ attributable to $K$-shell ionization (above the $K$-edge), $\mu_{K}\left(E_{i}\right)$, at an incident X-ray energy $E_{i}$ is equal to (see Fig. 4):

$\mu_{K}\left(E_{i}\right)=\left(\mu_{\mathrm{pe}}-\frac{\mu_{\mathrm{pe}}}{r}\right)=\mu_{\mathrm{pe}}\left(1-\frac{1}{r}\right)=\mu_{\mathrm{pe}}\left(1-\frac{\left(\mu-\mu_{K}\right)}{\mu}\right)$,

where $r$ is the 'edge ratio', defined as $\mu /\left(\mu-\mu_{K}\right)$, and $\mu$ and $\mu_{K}$ are the total and $K$-shell photoelectric cross sections, respectively, at the $K$-edge.

(The revised version of Fig. 4 is given overleaf.)

\section{Acknowledgements}

We thank Joshua L. Dickerson (University of Oxford, UK) for pointing out the error in the original paper.

\section{References}

Paithankar, K. S., Owen, R. L. \& Garman, E. F. (2009). J. Synchrotron Rad. 16, 152-162. 


\section{addenda and errata}
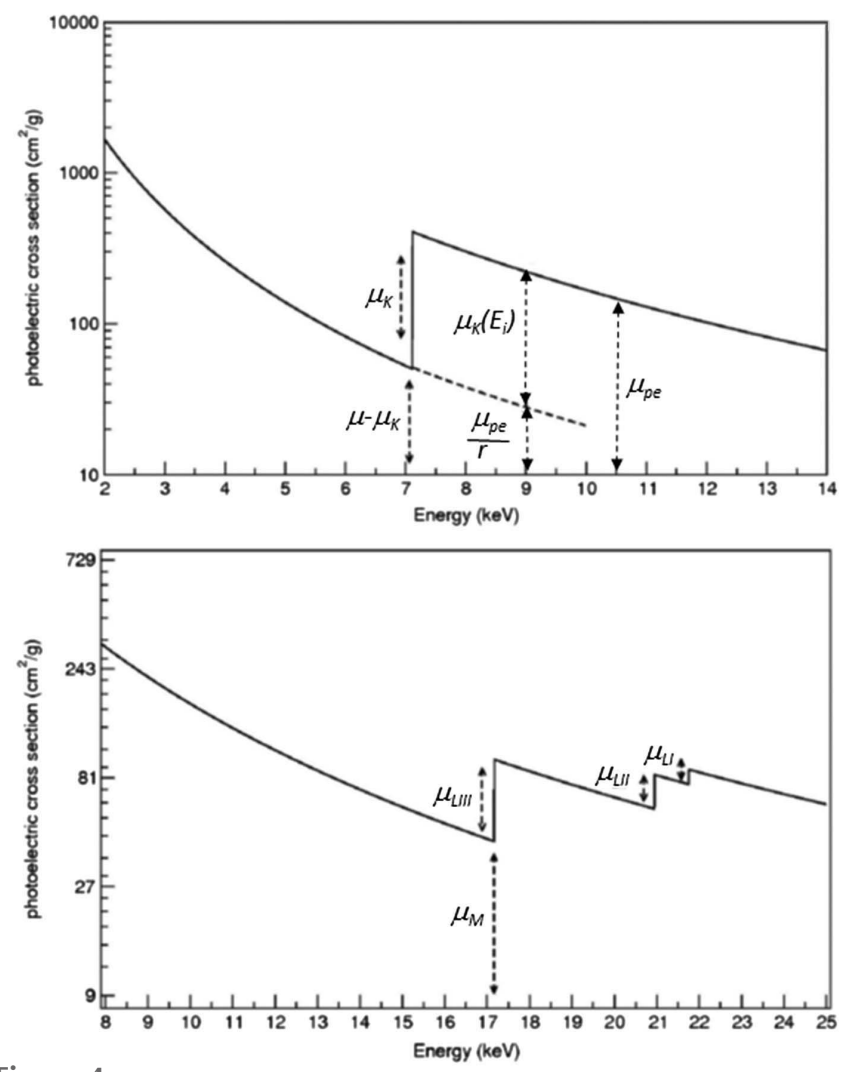

Figure 4

The photoelectric cross section of iron (top) and uranium (bottom) as a function of energy. $\mu_{K}, \mu_{L}$ and $\mu_{M}$ are the contributions of the $K$-, $L$ - and $M$-shell cross sections to the total photoelectric cross section, and $r$ is the edge ratio: $r=\mu /\left(\mu-\mu_{K}\right)$ and $\mu /\left(\mu-\mu_{L}\right)$ at any $K$ - and $L$-edge, respectively. 